\title{
Wettability, Thermal and Sliding Behavior of Thermally Sprayed Fly Ash Premixed Red Mud Coatings on Mild Steel
}

\author{
Harekrushna Sutar1,2*, Birupakshya Mishra'2, Rabiranjan Murmu², Sangram Patra², \\ Sarat Chandra Patra ${ }^{2}$, Subash Chandra Mishra ${ }^{3}$, Debashis Roy ${ }^{1}$ \\ ${ }^{1}$ Chemical Engineering Department, Jadavpur University, Kolkata, India \\ ${ }^{2}$ Chemical Engineering Department, Indira Gandhi Institute of Technology, Sarang, India \\ ${ }^{3}$ Metallurgical and Materials Engineering Department, National Institute of Technology, Rourkela, India \\ Email: ^h.k.sutar@gmail.com
}

How to cite this paper: Sutar, H., Mishra, B., Murmu, R., Patra, S., Patra, S.C., Mishra, S.C. and Roy, D. (2020) Wettability, Thermal and Sliding Behavior of Thermally Sprayed Fly Ash Premixed Red Mud Coatings on Mild Steel. Materials Sciences and Applications, 11, 12-26.

https://doi.org/10.4236/msa.2020.111002

Received: November 4, 2019

Accepted: December 28, 2019

Published: December 31, 2019

Copyright $\odot 2020$ by author(s) and Scientific Research Publishing Inc. This work is licensed under the Creative Commons Attribution International License (CC BY 4.0).

http://creativecommons.org/licenses/by/4.0/

\begin{abstract}
The present experimental work reveals the surface characteristics like wettability, thermal and sliding wear behaviour of plasma-sprayed red mud (RM) coatings premixed with fly ash (FA). Varying weight $\%$ of FA $(10,20,30$ and 40)-RM composite powder is used as precursor for coating. Atmospheric plasma-sprayed coatings are developed at different operating power like 5 $\mathrm{kW}, 10 \mathrm{~kW}, 15 \mathrm{~kW}$ and $20 \mathrm{~kW}$ separately on mild steel substrate. Tribological behaviour viz. sliding wear properties are studied at distinct operating load $(10 \mathrm{~N}, 15 \mathrm{~N}, 20 \mathrm{~N}, 25 \mathrm{~N})$, speed $(40 \mathrm{rpm}, 50 \mathrm{rpm}, 60 \mathrm{rpm}, 70 \mathrm{rpm})$ and track diameter of $100 \mathrm{~mm}$ using a pin on disc tribometer for duration of $30 \mathrm{mi}-$ nutes with 3 minute gap period for each experiment. The DSC and TGA experiments of the coatings are performed to understand the high temperature application areas. The contact angle result signifies the wettability of the prepared coatings is principally a function of composition. The reaction of surface roughness and spraying power is insignificant on water contact angle (WCA). In conclusion, the sliding wear experiments are optimized by Taguchi method to ascertain the influencing parameter on wear.
\end{abstract}

\section{Keywords}

Red Mud, Fly Ash, Contact Angle, DSC, TGA, Sliding Wear

\section{Introduction}

Plasma Spray Technology (PST) has been widely used in industrial practises for its versatility like high deposition rate, capacity to coat complex shapes, and abil- 
ity to process materials with high melting temperatures [1]. In general, PST uses feed materials in powder form with particles sizes ranging from 10 microns to 100 microns. The feed powder is entrained in a gas stream and injected into the plasma plume [2]. Development of water repellent coatings by PST is in focus for the researchers worldwide [3]. Thermal spray coatings find application to resist corrosion and wear. Investigation on surface behaviour like wettability prepared by PST using ceramic materials is limited. Changes in fluid contact angle in the interaction with materials surface play an important role in hydro machine components [4]. The wetting behaviour of coatings defines the efficiency and service life time of many engineering equipments.

Depending on water contact angle (WCA), the surface of all the materials and coatings is divided into hydrophobic or hydrophilic. WCA is an important factor for various practical applications, such as self-cleaning, antireflection, antifogging and antisticking [5] [6]. Superhydrophilic, hydrophilic, hydrophobic, and superhydrophobic surfaces are shown schematically in Figure 1. The wettability of the surfaces is controlled by surface energy, which in turn governed by surface chemical composition and surface roughness [7]. The contact angle formed between small liquid droplet and a perfectly smooth surface is expressed by Young [8]. The Equation (1) stated below is governed by Young's model.

$$
\cos \theta_{Y}=\frac{\gamma_{s v}-\gamma_{s l}}{\gamma_{l v}}
$$

where $\theta_{Y}$ is the apparent contact angle in Young's model. $\gamma_{s v}, \gamma_{s l}$ and $\gamma_{l v}$ are the interfacial surface energies (surface tension) associated with the solid-vapor, solid-liquid and liquid-vapor interfaces respectively. In practical, all real surfaces are rough. The roughness enhances the wettability. The surface models for wetting on rough surfaces are governed by either Wenzel or Cassie-Baxter state [9] [10]. In Wenzel model, a liquid droplet fully penetrates the rough surface and increases the solid-liquid interfacial area, as shown in Figure 2(a). On the other hand, in Cassie-Baxter model, the droplet rests on the top, trapping air within the grooves as illustrated in Figure 2(b). Equation (2) states the Wenzel model.

$$
\cos \theta_{w}=r \cos \theta_{Y},
$$

where $\theta_{w}$ is Wenzel apparent contact angle

$$
r=\text { Roughness ratio }=\frac{\text { True area of surface }}{\text { Projected area on the horizontal plane }} .
$$

For perfectly smooth surface, $r=1$ and Young's equation is recovered. But for real surface $r>1$.

For more complex conditions, Cassie and Baxter model is applicable and headed by Equation (3)

$$
\cos \theta_{C B}=f \cos \theta_{Y}+f-1,
$$

where $\theta_{C B}$ is Cassie and Baxter apparent contact angle. 


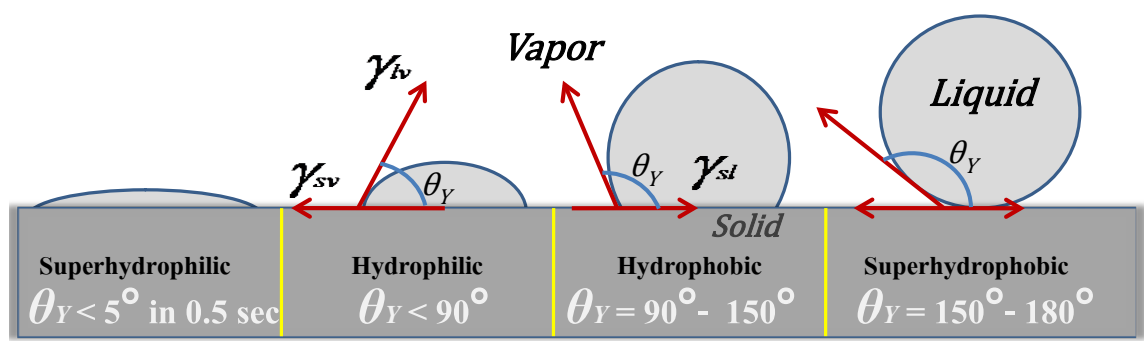

Figure 1. A droplet schematic diagram for superhydrophilic, hydrophilic, hydrophobic and superhydrophobic surfaces.

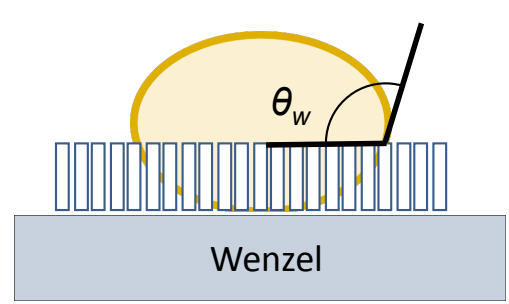

(a)

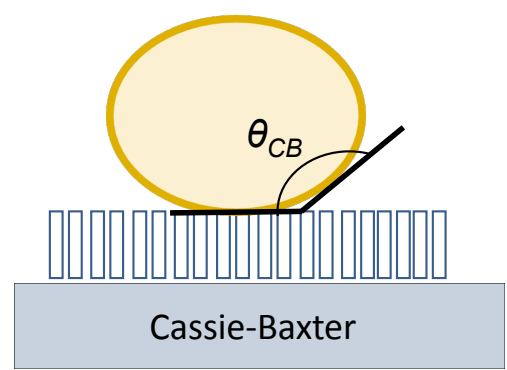

(b)

Figure 2. Schematic view of (a) Wenzel and (b) Cassie-Baxter models.

$$
f=\frac{\text { Surface area wetted by the liquid }}{\text { Projected area below the droplet }}
$$

$f$ is the area function and always less than unity. When $f=1$, Young's equation is recovered. But there have been discussions and disagreements over Wenzel and Cassie-Baxter equations by several surface engineers [11] [12] [13] [14].

The generation of red mud during alumina production and its disposal is a matter of concern. A broad literature review on red mud is reported [15]. The potential uses of red mud as reinforcing material to metals is widely accepted [16]-[21]. But over a decade researchers found it as suitable coating material [22] [23] [24] [25]. Tribological properties like erosion wear [26] [27], sliding wear [28] at different operating conditions are reported in literature. Thermal behaviour of red mud composite coatings at elevated temperature on mild steel is presented [29].

In the present paper, an attempt has been made to evaluate the wettability of plasma-sprayed red mud-fly ash composite coatings with respect to water. Surface chemistry of the prevailing coatings towards high temperature is observed through Differential Scanning Calorimetry (DSC) and Thermogravimetric Analysis (TGA) experiments. Design of experiments (DOE) is conducted to check the effect of operating parameters on wear.

\section{Materials and Methods}

\subsection{Collection of Coating Powder}

The principal raw material used in the present study is the industrial wastes like 
red mud and fly ash. Red mud is obtained from National Aluminium Company limited (NALCO), Damonjodi, India. Fly ash (FA) is picked up from Talcher Thermal Power Station (TTPS), Talcher, India. The as received precursor materials are dried in sunlight to remove moisture content and made bone dry. The dried material is ball milled separately and screened to obtain $80-100$ microns particles. Fly ash is reinforced to red mud to prepare the composite powder having $10 \%, 20 \%, 30 \%$ and $40 \%$ of fly ash by weight. Each powder mixture is blended continuously using a V-shaped blender to achieve homogeneity. Here after the material sent for coating.

\subsection{Plasma Coating}

Atmospheric Plasma Spraying (APS) technology is adopted to coat the prepared composite powder. The coating is conducted at Laser and Plasma technology division of Bhabha Atomic Research Centre, Mumbai, India using a PT-M1000 system (PlasmaTechnik AG, Wohlen, Switzerland) conjugated with an F4 plasmatron (Sulzer Metco). The plasma gun power is controlled by regulating input current and voltage. The outline of the APS unit is presented in Figure 3.

The coating is made at different torch power namely $5 \mathrm{~kW}, 10 \mathrm{~kW}, 15 \mathrm{~kW}$ and $20 \mathrm{~kW}$. A constant powder feed rate $(15 \mathrm{gm} / \mathrm{min})$ is maintained by help of turntable volumetric powder feeder. Argon is used as primary plasma generating gas, whereas Nitrogen as secondary gas agent. Plasma spraying was conducted at $90^{\circ}$ to base by feeding the powder material as external to gun. The detailed operating parameters of the coating deposition process are shown in Table 1.

In order to study the sliding wear, coating is made on one side cross section of cylindrical shaped mild steel substrate (see Figure 3 ) having length, $1=40 \mathrm{~mm}$ and diameter $\Phi=15 \mathrm{~mm}$. Mild steel samples of $\Phi=20 \mathrm{~mm}$ and thickness $3 \mathrm{~mm}$ are produced and fully coated to study the thermal behaviour at elevated temperature. Arithmetic mean roughness $\left(R_{a}\right)$ of the uncoated mild steel specimens is measured with a Mitutoyo Surftest SV 500 diamond-stylus roughness tester. The $R_{a}$ of uncoated specimens is reported to be $4.16 \mu \mathrm{m}$. The specimens are grit blasted with corundum particles for 4 minute at angle of $60^{\circ}$ and pressure 3.5

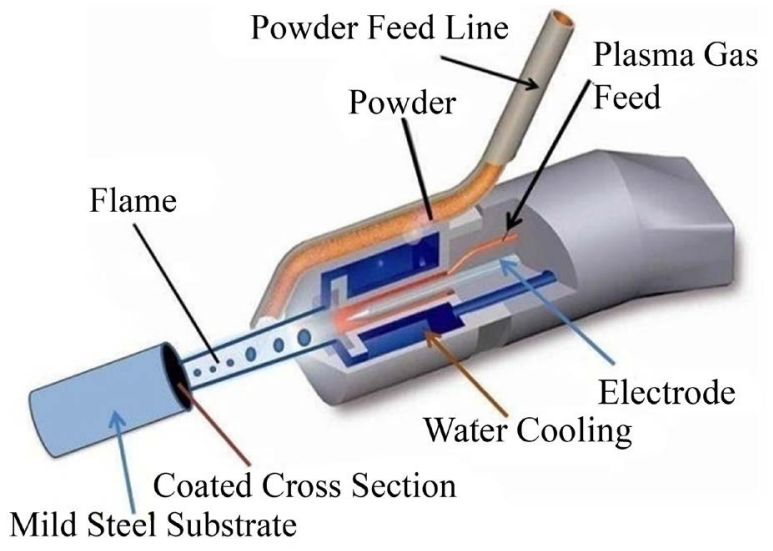

Figure 3. Schematic view of APS unit. 
Table 1. Operating parameters during coating deposition.

\begin{tabular}{cc}
\hline Operating parameters & Magnitude \\
\hline Plasma arc current (Ampere) & $250,250,300,400$ \\
Arc voltage (Volt) & $20,40,50,50$ \\
Torch input power (kW) & $5,10,15,20$ \\
Plasma gas (argon), (litre/min) & 30 \\
Secondary gas (nitrogen), (litre/min) & 3 \\
Career gas (argon) flow rate (litre/min) & 8 \\
Powder feed rate (gm/min) & 15 \\
Torch to base distance (mm) & 115 \\
Arc length range (mm) & $2,3,6,8,11$ \\
\hline
\end{tabular}

bars. The uncoated samples are ultrasonically cleaned using distilled water at $50^{\circ} \mathrm{C}$ for 15 minutes.

\subsection{Dry Sliding Wear Behaviour}

A pin on disc type friction and wear monitor (DUCOM; TR-20-M100) is adopted to study the sliding wear behaviour under un-lubricated condition. The tribometer with data acquisition system has a hardened ground steel disc (En-32, hardness $65 \mathrm{HRC}$, Roughness $0.5 \mu \mathrm{m}$ ) which rotates against the coating specimen. The schematic view of the in house tribometer is presented in Figure 4(a).

The hardened ground steel disc of the machine rotates with the help of a D.C. motor having a speed range of 0 - $200 \mathrm{rpm}$ with wear track diameter $0-160 \mathrm{~mm}$; this can yield a sliding speed of $0-10 \mathrm{~m} / \mathrm{s}$. Load is applied to the specimen by means of pulley and string arrangement. The tool possesses maximum load carrying capacity of $500 \mathrm{~N}$. The disc rotates against the pin as shown in Figure 4(b). The sliding wear experiments are conducted at a fixed track diameter of $100 \mathrm{~mm}$ with varying applied load $(10 \mathrm{~N}, 15 \mathrm{~N}, 20 \mathrm{~N}, 25 \mathrm{~N})$ and speed $(40 \mathrm{rpm}, 50 \mathrm{rpm}, 60$ rpm, $70 \mathrm{rpm}$ ) according to ASTM G-99 standard. Each coating sample is slid for 30 minutes. Mass loss (in gram) is measured for 10 batches with 3 minutes interval for individual coatings.

\subsection{Design of Experiment (DOE)}

We have used Taguchi optimization method [30] to design the experimental data corresponding to wear behaviour. Mass loss in gram is considered as response. Optimization is conducted using MINITAB-16 software. The factors considered in the study are fly ash content (composition), operating power, speed and applied load with four levels each. The operating condition implemented in the analysis is reported in Table 2.

Taguchi optimization is conducted in accordance with $L_{16}\left(4^{4}\right)$ orthogonal array (OA). The $S / N$ ratios for minimum mass loss (in gram) is calculated "under 


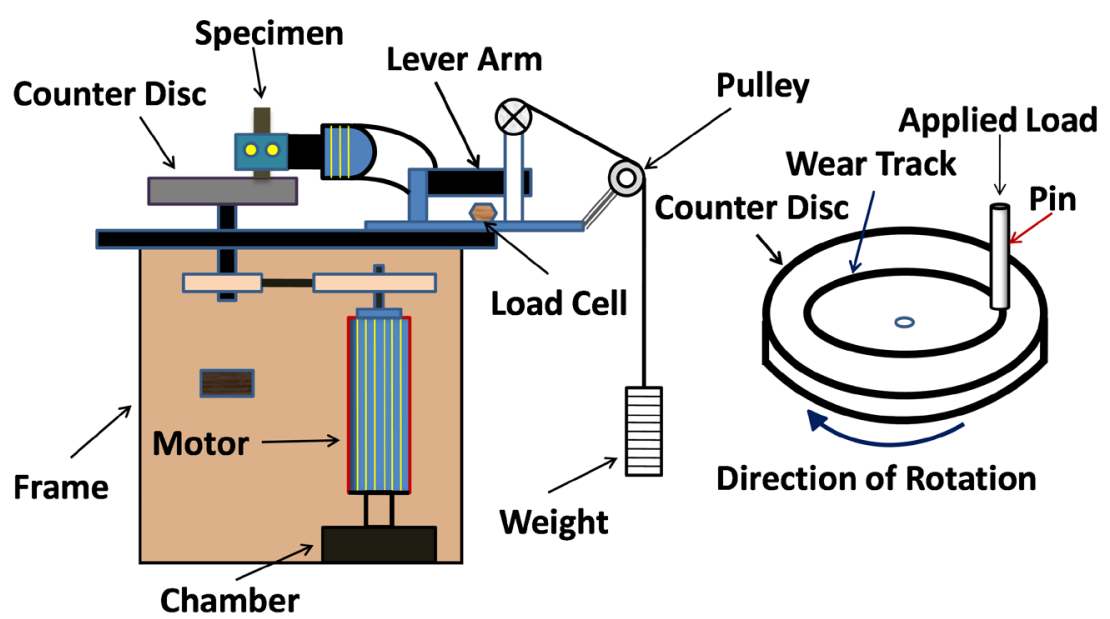

(a)

(b)

Figure 4. (a) Pin on disc tribometer (b) Scheme of pin on disc contact.

Table 2. Level of variables used in the experiment.

\begin{tabular}{cccccc}
\hline \multirow{2}{*}{ Control Factor } & \multicolumn{5}{c}{ Level } \\
\cline { 2 - 6 } & I & II & III & IV & Unit \\
\hline$P$ : Power & 5 & 10 & 15 & 20 & $\mathrm{~kW}$ \\
$C:$ Composition & 10 & 20 & 30 & 40 & $\mathrm{Wt} \%$ \\
$S$ : Speed & 40 & 50 & 60 & 70 & $\mathrm{rpm}$ \\
$L$ : Load & 10 & 15 & 20 & 25 & $\mathrm{~N}$ \\
\hline
\end{tabular}

lower is the better (LB)" characteristic. The signal-to-noise ratio for LB characteristics was calculated using the Equation (4).

$$
\frac{S}{N}=-10 \log \frac{1}{n}\left(\sum y^{2}\right)
$$

where " $n$ " is the repeated number trial conditions and " $y$ " is the sliding wear data.

\subsection{Study of Thermal Behaviour}

The coatings thermal behaviour is analysed using a DSC (Perkin-Elmer DSC 7, MA, USA) and TGA (Perkin-Elmer TGA, MA, USA) analysers as per ASTM E-2008 standards. The DSC tests are performed under oxidative environment with air flow rate of $15 \mathrm{ml} /$ minute. Coated samples are scanned at a heating rate of $10^{\circ} \mathrm{C}$ per minute from atmospheric temperature to $1000^{\circ} \mathrm{C}$. In TGA test the as prepared coated samples are heated from room temperature to $1000^{\circ} \mathrm{C}$ at a heating rate of $5^{\circ} \mathrm{C}$ per minute and air flow rate of $15 \mathrm{ml} /$ minute to analyse their degradation behaviour.

\section{Results and Discussion}

The static water contact angle of the as sprayed coatings is measured using a 
contact angle (CA) analyser (ACAmD2A01, Apex Instruments Pvt. Ltd., Germany) with conventional sessile-drop method coupled with tangent line facility. The analyser places a water droplet of $10 \mu \mathrm{L}$ on the coating substrate. The experiments are conducted at normal atmospheric temperature and pressure. The results are shown in Figure 5. It is seen that, the WCA is maximum for 10\% FA content coating. The contact angle decreases with increase of FA content in the coatings. As observed the maximum value of contact angle is $\approx 80^{\circ}$ and minimum is $\approx 30^{\circ}$. The obtained result evidences hydrophilic nature of the prepared coatings. Hydrophilicity increases with FA content of the formulated coatings. The water attracting property of the coatings is attributing to high amount of silica $\left(\mathrm{SiO}_{2}\right)$ content in fly ash. As fly ash is hygroscopic in nature and its presence in the coating materials specially enhances the affinity for water. The water contact angle results signify the plasma spray (PS) operating power has infinitesimal effect on it. Beside an attempt has been made to correlate the coating surface roughness with water contact angle. The surface roughness of the coatings is measured as per DIN EN ISO 13565-2 standard using the equipment stated earlier. Assuming the surface to be isotropic, a path of $5 \mathrm{~mm}$ is traced by the diamond stylus across the coating. Each roughness test is conducted three times and the average value is reported (Table 3 ).

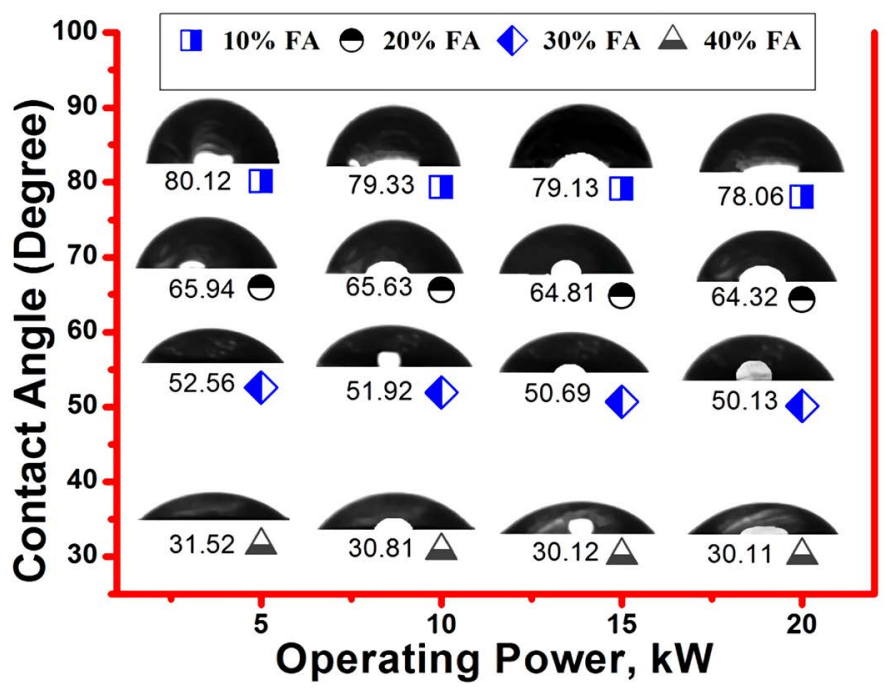

Figure 5. Water Contact Angle (WCA) of the available coatings.

Table 3. Data pertaining to surface roughness of the coatings.

\begin{tabular}{lcccc}
\hline & \multicolumn{4}{c}{ Plasma Gun Power, kW } \\
\cline { 2 - 4 } Coating Type & 5 & \multicolumn{4}{c}{10} & 15 & 20 \\
\cline { 2 - 5 } & \multicolumn{4}{c}{ Arithmetic Mean Roughness $\left(R_{\mathrm{a}}\right), \mu \mathrm{m}$} \\
\hline RM-10\% FA & 12.36 & 12.15 & 11.24 & 10.11 \\
RM-20\% FA & 15.29 & 15.23 & 14.35 & 13.38 \\
RM-30\% FA & 21.64 & 21.01 & 20.39 & 20.18 \\
RM-40\% FA & 33.13 & 32.18 & 31.61 & 30.55 \\
\hline
\end{tabular}


The effect of operating power on surface roughness is not significant. But with addition of fly ash the arithmetic mean roughness of the coating surface increases. The surface roughness is maximum $(\approx 33 \mu \mathrm{m})$ for $40 \%$ FA content coatings. The practical reasons behind the out coming results are unrecognizable. Although the wettability and the surface roughness of the prepared coatings increases with fly ash addition, but both the properties are negligibly reacted by operating power. Probably when power increases, the enthalpy content of the plasma generating gases rises. This might cause proper melting of the feed powder, new phase formation during plasma spraying and possible changes in the chemical nature of the coated surface.

Thermal behaviour is studied by conducting both DSC and TGA experiments implementing the methods as stated earlier. The DSC curve corresponding to the coatings made at $5 \mathrm{~kW}$ is presented in Figure 6 . The pure red mud coating absorbs heat up to a temperature of $550^{\circ} \mathrm{C}\left(T H_{\max }\right) . \mathrm{FA}$ addition alters the magnitude of $T H_{\max }$. The RM-40\% FA coatings absorb energy up to $708^{\circ} \mathrm{C}$ as shown in Figure 6. It is observed that DSC curve for different fly ash content coatings peaks at different temperatures. It is seen that, the peak $\left(T H_{\max }\right)$ shifts towards right. The originated DSC curve for pure red mud coating holds highest broad area.

The results corresponding to thermo gravimetric analysis (TGA) of the prepared coatings are reported in Figure 7. Attributing to the previous explanation regarding the hygroscopic character of fly ash, the weight loss is extreme (up to 89\%) for RM-40\% FA composite coating. The results are obvious as FA content increases; the composite coating carries additional moisture and hence dehydrates to a greater extent. The maximal weigh loss of each coating and relative temperature is shown in Figure 7. Scanning electron microscope (SEM; JEOL, JSM-6480 LV) is implemented to observe surface morphology of the coatings

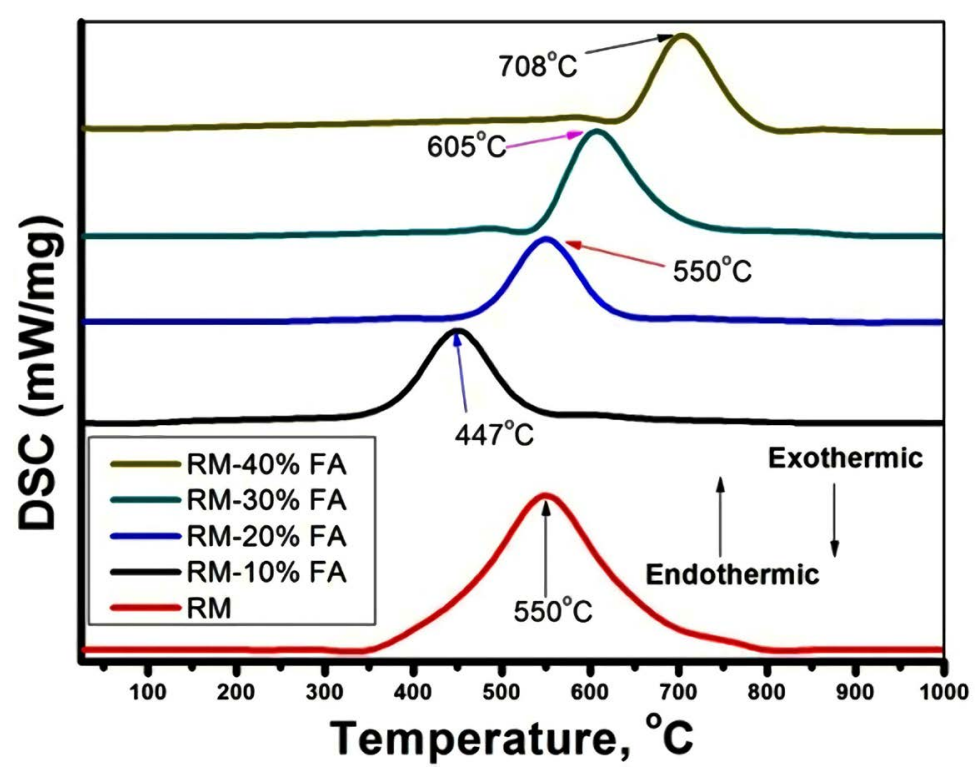

Figure 6. Originated DSC curves of the prevailing coatings made at $5 \mathrm{~kW}$. 


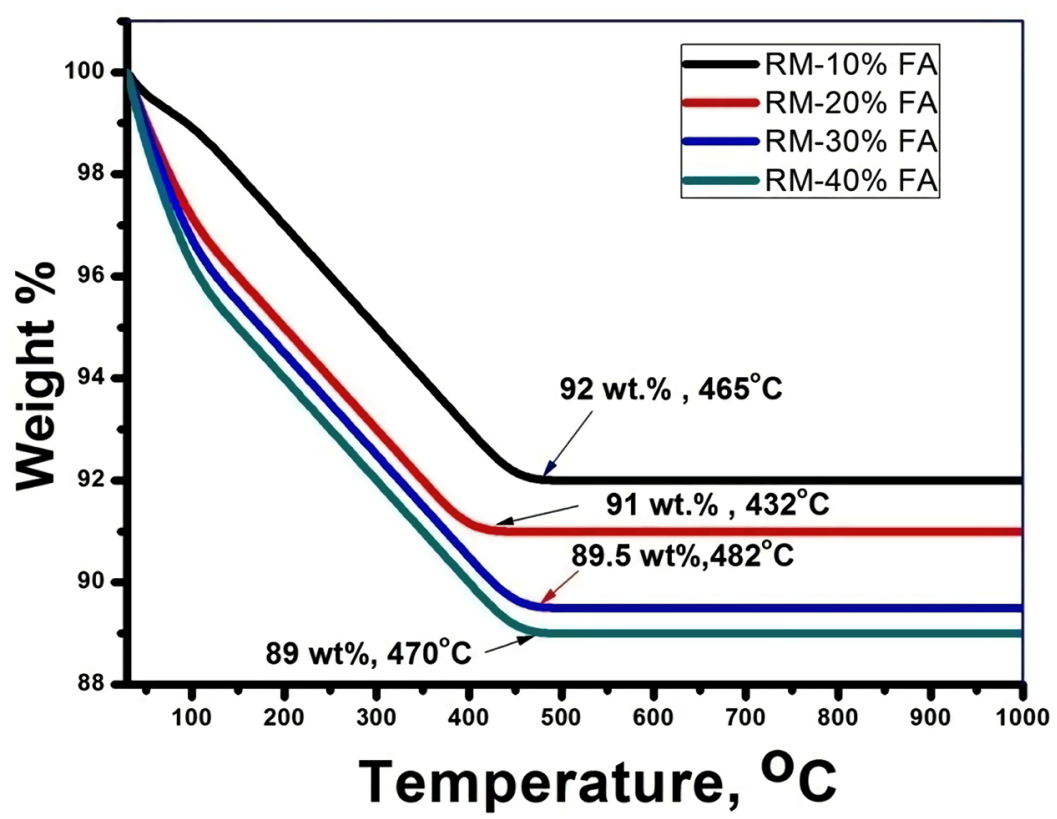

Figure 7. Thermo gravimetric analysis (TGA) of the prepared coatings at $5 \mathrm{~kW}$.

after thermal experiments. Images (see Figure 8) reveal crack formation of the coatings and fusion of the coating particles. Thermal behaviour of the coatings made at other operating power is not studied.

Statistical analysis of the wear rate (mass loss) was made using the software MINITAB 16. $L_{16}$ orthogonal array is used to design the experiment as stated earlier. The sliding wear behaviour is designed and presented in Table 4. The mean of the $S / N$ ratio is found to be $31.38785 \mathrm{~dB}$. Figure 9 shows graphically the effect of control factors on wear rate. According to process parameter settings the higher will be the $S / N$ ratio the minimum will be the variance and optimum will be the quality. From Figure 9, it is observed that the factor combination of $P_{1}, C_{1}, S_{1}$ and $L_{4}$ gives minimum wear rate. The minimum wear rate for the developed composite coatings is obtained when the power $(P)$, composition $(C)$ and speed $(S)$ are at the lowest level and load $(L)$ at the highest level. Figure 9(b) reveals the mean effect of control factors on mass loss. It is noted that, there is continuous increase in mass loss up to $15 \mathrm{~kW}$ operating power. Afterwards there is a marginal fall at $20 \mathrm{~kW}$. The trend is similar for the factor composition (C). In our experiment the wear rate is continuously increasing with speed. The results are obvious because, increase in sliding velocity results in increased rubbing action at the coating and steel disc interface and consequently the wear rate increases. However, the mass loss shows both increasing and decreasing trends with load rate. With increase in load, there will be thermal softening of the coating surface and loosening of the coating material and hence increase in wear rate. But at higher load there will be dislodging of the coating and wear debris forms and whiskers at the interface. These whiskers take over the load and reduce the wear rate. The $S / N$ ratio response is given in Table 5. It is concluded from Table 5 that, spraying power is the most influencing factor followed by 


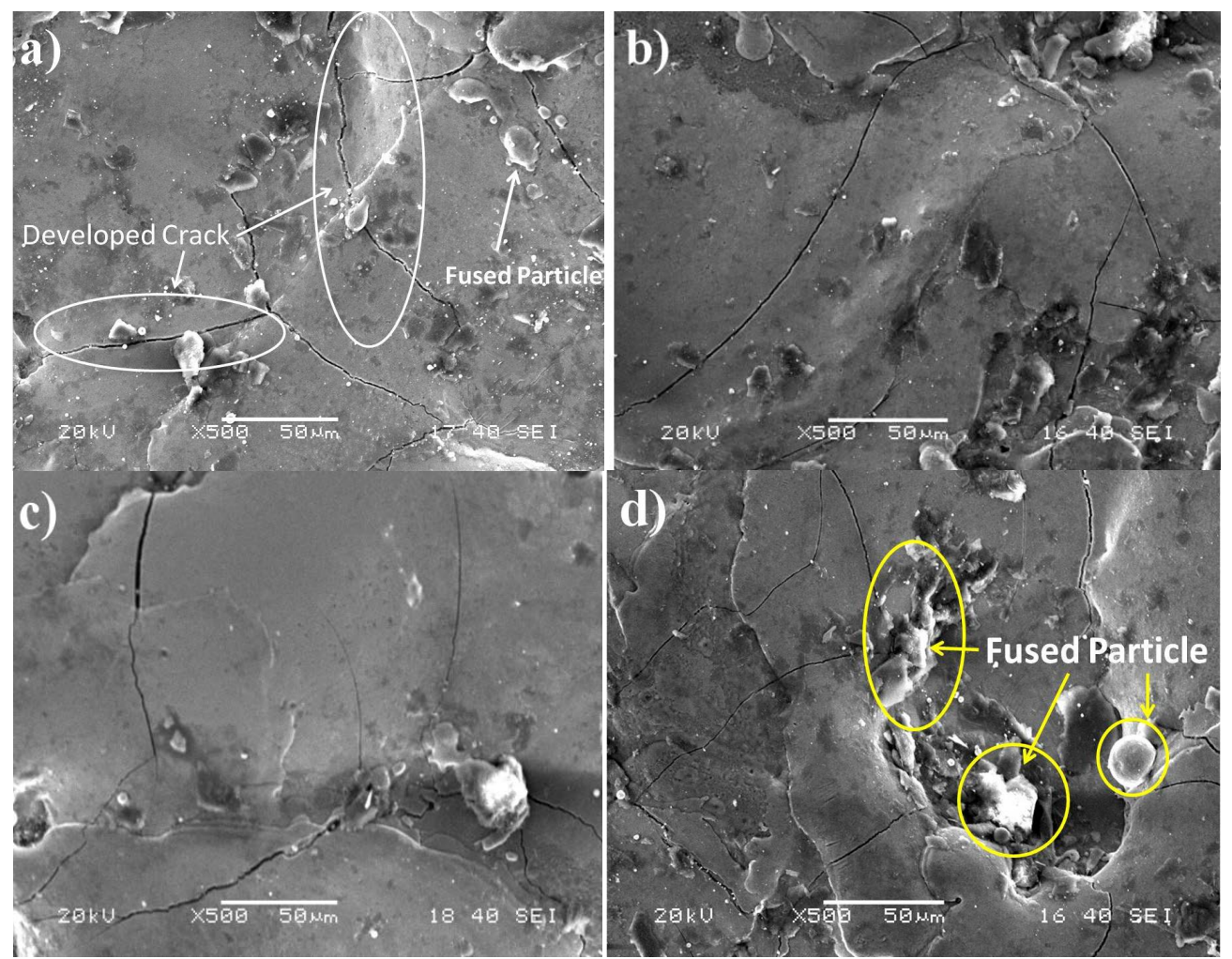

Figure 8. Surface morphology of the coatings; (a) RM-10\% FA, (b) RM-20\% FA, (c) RM-30\% FA and (d) RM- $40 \%$ FA at $1000^{\circ} \mathrm{C}$.

Table 4. Test conditions with output results using $L_{16}$ orthogonal array.

\begin{tabular}{ccccccc}
\hline $\mathrm{L}_{16}$ & $\begin{array}{c}\text { Power } \\
(\mathrm{kW})\end{array}$ & $\begin{array}{c}\text { Composition } \\
(\text { Wt \% FA) }\end{array}$ & $\begin{array}{c}\text { Speed, } \\
(\mathrm{rpm})\end{array}$ & $\begin{array}{c}\text { Load } \\
(\mathrm{N})\end{array}$ & $\begin{array}{c}\text { Wear Rate } \\
(\mathrm{gm})\end{array}$ & $\begin{array}{c}S / N \text { ratio } \\
(\mathrm{dB})\end{array}$ \\
\hline 1 & 5 & 10 & 40 & 10 & 0.001456 & 56.73677 \\
2 & 5 & 20 & 50 & 15 & 0.00146 & 56.71294 \\
3 & 5 & 30 & 60 & 20 & 0.00186 & 54.60974 \\
4 & 5 & 40 & 70 & 25 & 0.00164 & 55.70312 \\
5 & 10 & 10 & 50 & 20 & 0.00236 & 52.54176 \\
6 & 10 & 20 & 40 & 25 & 0.00358 & 48.92234 \\
7 & 10 & 30 & 70 & 10 & 0.04456 & 27.02110 \\
8 & 10 & 40 & 60 & 15 & 0.04125 & 27.69152 \\
9 & 15 & 10 & 60 & 25 & 0.16489 & 15.65611 \\
10 & 15 & 20 & 70 & 20 & 0.17548 & 15.11545 \\
11 & 15 & 30 & 40 & 15 & 0.18452 & 14.67913 \\
12 & 15 & 40 & 50 & 10 & 0.16958 & 15.41251 \\
13 & 20 & 10 & 70 & 15 & 0.16548 & 15.62509 \\
14 & 20 & 20 & 60 & 10 & 0.17546 & 15.11644 \\
15 & 20 & 30 & 50 & 25 & 0.18547 & 14.63453 \\
16 & 20 & 40 & 40 & 20 & 0.15799 & 16.02741 \\
\hline
\end{tabular}




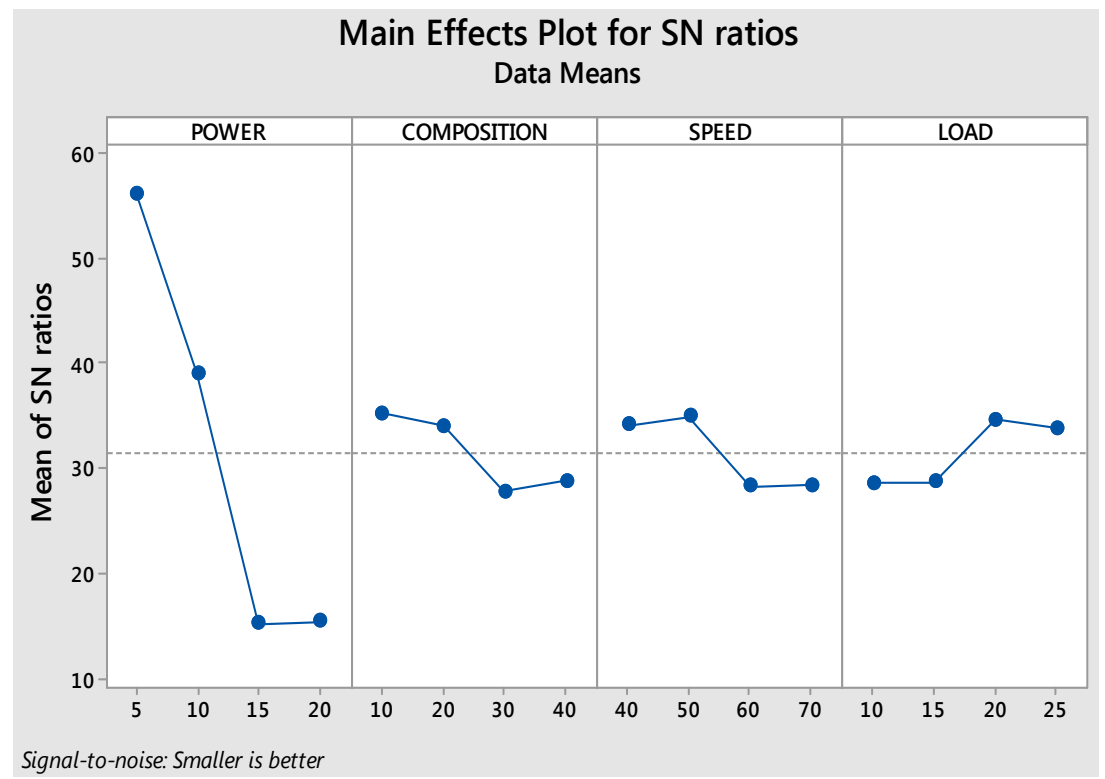

(a)

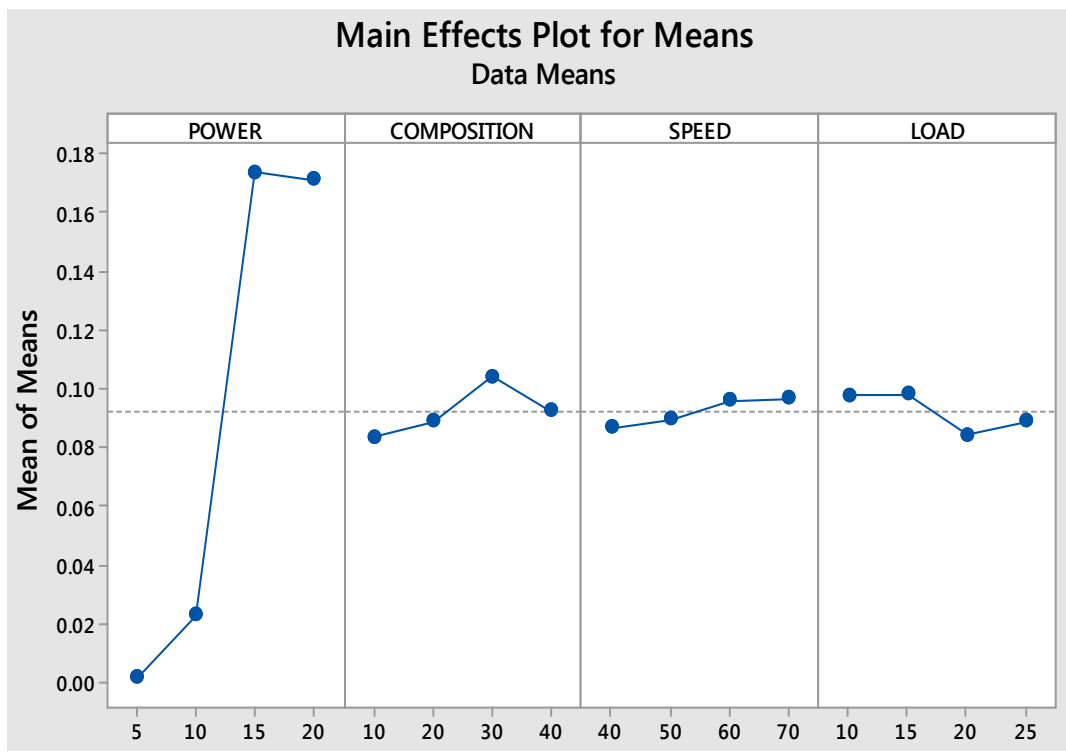

(b)

Figure 9. (a) Effect of control factors on wear rate ( $S / N$ ratio), (b) Effect of control factors on wear rate (Mean).

Table 5. Response table for signal to noise ratios.

\begin{tabular}{ccccc}
\hline Level & Power & Composition & Speed & Load \\
\hline I & 55.94 & 35.14 & 34.09 & 28.57 \\
II & 39.04 & 33.97 & 34.83 & 28.68 \\
III & 15.22 & 27.74 & 28.27 & 34.57 \\
IV & 15.35 & 28.71 & 28.37 & 33.73 \\
Delta $(\Delta)$ & 40.72 & 7.4 & 6.56 & 6 \\
Rank & 1 & 2 & 3 & 4 \\
\hline
\end{tabular}


composition, speed and load. Further statistical analysis is carried out (ANOVA) to justify the insignificant factor. Table 6 shows the results of the ANOVA for mass loss. The analysis is carried out with $5 \%$ level of significance ( $95 \%$ level of confidence). " $P$ " value, less than 0.05 for a particular parameter, indicates that it has the major effect on the responses. The $6^{\text {th }}$ column of Table 6 designates the order of significance of all factors. The ANOVA results signify the factor power has the greatest static influence $(P=0.006)$ followed by composition, speed and load. The correlation between mass loss ( $M L$, non-variable factor) and variable factors (power, composition, speed, and load) is developed by multiple linear regressions and is given by Equation (5).

$$
M L=-0.0887+0.01318 P+0.000423 C+0.000389 S-0.00081 L .
$$

Finally the confirmation experiments are conducted. It is the final step in the design of experiment process. The test is performed to validate the conclusions drawn during the analysis phase. From the model, the confirmation test results are reported in Table 7, and the average improvement is found to be $1.2 \%$.

\section{Conclusion}

The above experimental research concludes salient features of the prepared ceramic coatings. The plasma-sprayed coatings of red mud and fly ash composites may find suitable tribological applications. Fly ash can be a beneficial reinforcing agent to red mud. There is significant improvement in thermal properties like stability towards high temperature. These coatings are fit to use in elevated temperature areas with excellent thermal resistance. The experimental findings remark

Table 6. ANOVA table for wear rate.

\begin{tabular}{cccccc}
\hline SOURCE & DOF & Adj SS & Adj MS & $F$-Value & $P$-Value \\
\hline Power & 3 & 4720.7 & 1573.57 & 40.23 & 0.006 \\
Composition & 3 & 165 & 54.99 & 1.41 & 0.393 \\
Speed & 3 & 151.9 & 50.65 & 1.29 & 0.418 \\
Load & 3 & 123.6 & 41.21 & 1.05 & 0.483 \\
Error & 3 & 117.3 & 39.11 & & \\
Total & 15 & 5278.6 & & & \\
\hline
\end{tabular}

DOF: degrees of freedom; Adj SS: adjusted sum of squares; Adj MS: adjusted mean squares.

Table 7. Confirmation test for mass loss.

\begin{tabular}{|c|c|c|c|}
\hline \multirow{2}{*}{ Level } & \multicolumn{2}{|c|}{ Optimal Process Parameters (Mass Loss in gram) } & \multirow{2}{*}{ Error \% } \\
\hline & Prediction & Experimental & \\
\hline$P_{1} C_{1} S_{1} L_{1}$ & 0.001231 & 0.001456 & 1.50 \\
\hline$P_{2} C_{1} S_{2} L_{3}$ & 0.002908 & 0.002360 & 1.80 \\
\hline$P_{3} C_{4} S_{2} L_{1}$ & 0.153770 & 0.695800 & 0.90 \\
\hline$P_{4} C_{4} S_{1} L_{3}$ & 0.168680 & 0.157990 & 0.60 \\
\hline
\end{tabular}


the wettability of the coatings. An improvement in wetting property is seen with fly ash augmentation indicating it to be a function of primarily the fly ash content. But the wetting characteristic is almost independent on spraying power and surface roughness. In this study, the Taguchi optimization result shows that the control factor power is the most influential factor on wear. Although factors like composition, speed and load are less influential, but cannot be neglected. The present work may be extended to find many other coating properties like erosion wear, mechanical strength. The chemical stability of the coatings may be evaluated by the study of corrosion wear properties to recognize definite application areas.

\section{Conflicts of Interest}

The authors declare no conflicts of interest regarding the publication of this paper.

\section{References}

[1] Cai, Y., Coyle, T.W., Azimi, G. and Mostaghimi, J. (2016) Superhydrophobic Ceramic Coatings by Solution Precursor Plasma Spray. Scientific Reports, 6, Article No. 24670. https://doi.org/10.1038/srep24670

[2] Oksa, M., Turunen, E., Sohunen, T., Varis, T. and Hannula, S.P. (2011) Optimization and Characterization of High Velocity Oxy-Fuel Sprayed Coatings: Techniques, Materials, and Applications. Coatings, 1, 17-52. https://doi.org/10.3390/coatings1010017

[3] Padture, N.P., Gell, M. and Jordan, E.H. (2002) Thermal Barrier Coatings for Gas-Turbine Engine Applications. Science, 296, 280-284. https://doi.org/10.1126/science.1068609

[4] Komarov, P., Celko, L., Jech, D., Papula, M., Slamecka, K., Horynova, M., Klakurkova, L. and Kaiser, J. (2017) Investigations of Wettability of Wear Resistant Coatings Produced by Atmospheric Plasma Spraying. Solid State Phenomena, 270, 230-235. https://doi.org/10.4028/www.scientific.net/SSP.270.230

[5] Asmatulu, R., Khan, W.S., Reddy, R.J. and Ceylan, M. (2014) Synthesis and Analysis of Injection-Molded Nanocomposites of Recycled High-Density Polyethylene Incorporated with Graphene Nanoflakes. Polymer Composites, 36, 1565-1573. https://doi.org/10.1002/pc.23063

[6] Nuraje, N., Khan, W.S., Lei, Y., Ceylan, M. and Asmatulu, R. (2012) Superhydrophobic Electrospun Nanofibers. Journal of Materials Chemistry A, 1, 1929-1946. https://doi.org/10.1039/C2TA00189F

[7] Xu, P.Y., Coyle, T.W., Pershin, L. and Mostaghimi, J. (2018) Superhydrophobic Ceramic Coating: Fabrication by Solution Precursor Plasma Spray and Investigation of Wetting Behaviour. Journal of Colloid and Interface Science, 523, 35-44. https://doi.org/10.1016/j.jcis.2018.03.018

[8] Bahgat Radwan, A., Abdullah, A. and Alnuaimi, N. (2017) Recent Advances in Corrosion Resistant Superhydrophobic Coatings. Corrosion Reviews, 36, 127-153. https://doi.org/10.1515/corrrev-2017-0012

[9] Zhang, F., Robinson, B.W., Villiers-Lovelock, H.D., Wood, R.J. and Wang, S.C. Wettability of Hierarchically-Textured Ceramic Coatings Produced by Suspension HVOF Spraying. Journal of Materials Chemistry A, 3, 13864-13873. 
https://doi.org/10.1039/C5TA02130H

[10] Nishino, T., Meguro, M., Nakamae, K., Matsushita, M. and Ueda, Y. (1999) The Lowest Surface Free Energy Based on CF3 Alignment. Langmuir, 15, 4321-4323. https://doi.org/10.1021/la981727s

[11] Gao, L. and McCarthy, T.J. (2007) How Wenzel and Cassie Were Wrong. Langmuir, 23, 3762-3765. https://doi.org/10.1021/la062634a

[12] Shirtcliffe, N.J., McHale, G., Newton, M.I. and Perry, C.C. (2005) Wetting and Wetting Transitions on Copper-Based Super-Hydrophobic Surfaces. Langmuir, 21, 937-943. https://doi.org/10.1021/la048630s

[13] Nosonovsky, M. and Bhushan, B. (2008) Roughness-Induced Superhydrophobicity: A Way to Design Non-Adhesive Surfaces. Journal of Physics: Condensed Matter, 20, Article ID: 225009. https://doi.org/10.1088/0953-8984/20/22/225009

[14] Vedantam, S. and Panchagnula, M.V. (2007) Phase Field Modeling of Hysteresis in Sessile Drops. Physical Review Letters, 99, Article ID: 176102. https://doi.org/10.1103/PhysRevLett.99.176102

[15] Sutar, H., Mishra, S.C., Sahoo, S.K., Chakraverty, A.P. and Maharana, H.S. (2014) Progress of Red Mud Utilization: An Overview. American Chemical Science Journal, 4, 255-279. https://doi.org/10.9734/ACSJ/2014/7258

[16] Panwar, N., Poonia, R.P., Singh, G., Dabral, R. and Chauhan, A. (2017) Effect of Lubrication on Sliding Wear of Red Mud Particulate Reinforced Aluminium Alloy 6061. Tribology in Industry, 39, 307-318. https://doi.org/10.24874/ti.2017.39.03.05

[17] Dabral, R., Panwar, N., Dang, R., Poonia, R.P. and Chauhan, A. (2017) Wear Response of Aluminium 6061 Composite Reinforced with Red Mud at Elevated Temperature. Tribology in Industry, 39, 391-399.

https://doi.org/10.24874/ti.2017.39.03.14

[18] Prasad, N., Sutar, H., Mishra, H.C., Sahoo, S.K. and Acharya, S.K. (2013) Dry Sliding Wear Behavior Aluminium Matrix Composite Using Red Mud an Industrial Waste. International Research Journal of Pure and Applied Chemistry, 3, 59-74. https://doi.org/10.9734/IRJPAC/2013/2906

[19] Panwar, N., Saini, S. and Chauhan, A. (2019) Frictional Study of Al 6061 Red-Mud Composite under the Influence of Different Process Parameters. Tribology in Industry, 41, 199-211. https://doi.org/10.24874/ti.2019.41.02.06

[20] Chinta, N.D., Selvaraj, N. and Mahesh, M. (2016) Dry Sliding Wear Behaviour of Aluminum Red Mud Tungsten Carbide Hybrid Metal Matrix Composites. IOP Conference Series. Materials Science and Engineering, 149, Article ID: 012094. https://doi.org/10.1088/1757-899X/149/1/012094

[21] Acharya, S.K., Dikshit, V. and Mishra, P. (2008) Erosive Wear Behaviour of Redmud Filled Metal Matrix Composite. Journal of Reinforced Plastics and Composites, 27, 145-152. https://doi.org/10.1177/0731684407082543

[22] Satapathy, A., Sutar, H., Mishra, S.C. and Sahoo, S.K. (2013) Characterization of Plasma Sprayed Pure Red Mud Coatings: An Analysis. American Chemical Science Journal, 3, 151-163. https://doi.org/10.9734/ACSJ/2013/3218

[23] Sutar, H., Roy, D., Mishra, S.C., Chakraverty, A.P. and Maharana, H.S. (2014) Friction and Wear Behaviour of Plasma Sprayed Fly Ash Added Red Mud Coatings. Physical Science International Journal, 5, 61-73. https://doi.org/10.9734/PSIJ/2015/12624

[24] Sutar, H., Roy, D. and Mishra, S.C. (2015) Effect of Fly Ash and Carbon Reinforcement on Dry Sliding Wear Behaviour of Red Mud. Indian Journal of Materials 
Science, 2015, Article ID: 296324. https://doi.org/10.1155/2015/296324

[25] Sutar, H., Mishra, S.C., Sahoo, S.K., Maharana, H.S. and Chakraverty, A.P. (2014) Tribological Aspects of Thermally Sprayed Red Mud-Fly Ash and Red Mud-Al Coatings on Mild Steel. American Chemical Science Journal, 4, 1014-1031. https://doi.org/10.9734/ACSJ/2014/12691

[26] Sutar, H., Mishra, S.C., Sahoo, S.K., Satapathy, A. and Kumar, V. (2012) Morphology and Solid Particle Erosion Wear Behavior of Red Mud Composite Coatings. Natural Science, 4, 832-838. https://doi.org/10.4236/ns.2012.411111

[27] More, S.R., Bhatt, D.V. and Menghani, J.V. (2017) Study of the Parametric Performance of Solid Particle Erosion Wear under the Slurry Pot Test Rig. Tribology in Industry, 39, 471-481. https://doi.org/10.24874/ti.2017.39.04.06

[28] Sutar, H., Roy, D., Mishra, S.C. and Murmu, R. (2016) Sliding Wear Performance Evaluation of Red Mud (RM), RM + Fly Ash (FA) and RM + FA + Al Coatings on Mild Steel. Materials Sciences and Applications, 7, 171-179. https://doi.org/10.4236/msa.2016.73017

[29] Sutar, H., Roy, D., Mishra, S.C., Patra, S. and Murmu, R. (2018) Thermal and Dry Sliding Wear Behavior of Plasma Sprayed Red Mud-Fly Ash Coatings on Mild Steel. Tribology in Industry, 40, 117-128. https://doi.org/10.24874/ti.2018.40.01.11

[30] Sudheer, M., Ravikantha, P., Raju, K. and Thirumaleshwara, B. (2012) Optimization of Dry Sliding Wear Performance of Ceramic Whisker Filled Epoxy Composites Using Taguchi Approach. Advances in Tribology, 2012, Article ID: 431903. https://doi.org/10.1155/2012/431903 